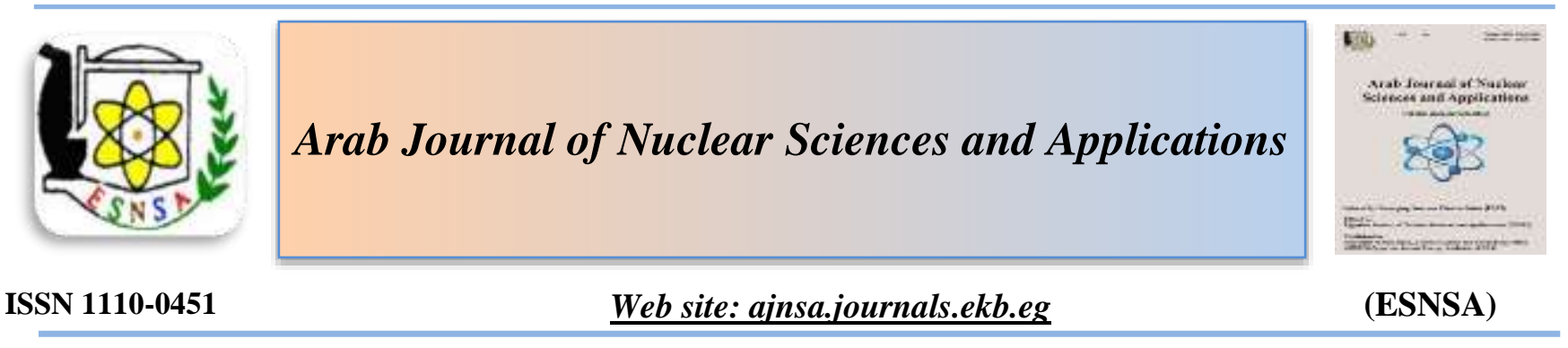

\title{
Calculation of Corrosion Rate in Ex-reactor Considering the Reactor Effects on the (VVER-1000) fuel clad
}

\author{
Leila Ramezan ${ }^{1}$, Masoud Mansouri² ${ }^{2}$ and Mohammad Rahgoshay ${ }^{3 *}$ \\ ${ }^{1}$ Department of of Nuclear Engineering, Science and Research Branch, Islamic Azad University, Tehran, Iran; E- \\ mail: leila.ramezani9@yahoo.com \\ ${ }^{2}$ Egyptian Nuclear Engineering, Science and Research Branch, Islamic Azad University, Tehran, Iran; E-mail: \\ dmmansouri@gmail.com \\ ${ }^{3}$ Department of Nuclear Engineering, Science and Research Branch, Islamic Azad University, Tehran, Iran; E-mail: \\ m.rahgoshay@gmail.com
}

\begin{abstract}
Received $8^{\text {th }}$ Aug. 2019 Accepted 16 ${ }^{\text {th }}$ June 2020

(he Zirconium oxidation is of high importance, so numerous studies are accomplished in order to study the layer and various methods have been proposed for reducing its growth. While, many models are developed to calculate the thickness of this layer both for external and operation condition of the reactor. These models are used for calculations, designation and studying the function of fuel rod. The corrosion of fuel clad is defined in two ways, initially the corrosion is calculated regardless of reactor's effect, so called Ex-reactor, then it is computed by taking into account the effects, including irradiation, Lithium concentration, etc. which is known as In-reactor. The present paper aims at calculating the corrosion rate of fuel rod clad for Bushehr Reactor in Ex-reactor, and finally the reactor will be proposed by considering the effects.
\end{abstract}

Keywords: Zirconium; Corrosion, Fuel Clad, Ex-Reactor

\section{Introduction}

Zirconium alloys are principally utilized in highly corrosive environments, such as nuclear reactors with specific conditions connected to the fuel burn up cycles and water chemistry. In operation mode, nuclear fuel rods are immersed in the primary water, which leads to waterside corrosion, as well as hydrogen ingress. Zirconium alloys readily react with oxygen and the formation of a thin passivation layer is expected. Corrosion resistance of zirconium alloys is improved by intentional development of thicker passivation layer of zirconium oxide. It is deemed that a submicrometer thin layer of zirconium dioxide is rapidly formed in the surface and stops the further diffusion of oxygen to the bulk and the subsequent oxidation.

For calculating the oxide layer thickness in Exreactor, by solving the Fick's equation and obtaining the oxygen concentration for each section of fuel, the corrosion rate can be calculated. By considering the effects, such as thermal flux and lithium concentration, it is possible to calculate the corrosion rate, and the results will reveal the amount of increase in the corrosion.

\section{EX-REACTOR CORROSION MODELLING}

In this case, it would be desirable to utilize Fick's law equation for calculating the corrosion rate. The diffusion equation for a cylinder, which

Corresponding author:dmmansouri@gmail.com

DOI:10.21608/ajnsa.2020.29241.1350

(C) Scientific Information, Documentation and Publishing Office (SIDPO)-EAEA 
is function of concentration and cylinder radius can be written as below, in which $\mathrm{r}$ and $\mathrm{t}$ is cylindrical radius and time, respectively. In what follows, the First Fick's Law is presented which is used for diffusion in steady state. That is, the concentration difference varies, as time passes and it is merely depended on the distance $[1,2]$.

$$
J=-D \frac{d c}{d r}
$$

So, we have:

$\mathrm{J}$ : Diffusion flux ( $\left.\mathrm{mol} / \mathrm{m}^{2} . \mathrm{s}\right)$

D: Diffusion coefficient $\left(\mathrm{m}^{2} / \mathrm{s}\right)$

C: Concentration $\left(\mathrm{mol} / \mathrm{m}^{3}\right)$

R: Diffusion distance (m)

There exists a direct relation between average velocity of the particles and $\mathrm{D}$, and the velocity is depended on temperate, fluid viscosity and particles size. It is more common to adopt the second Fick's law for unsteady perimeters, which is as follow for cylindrical coordination:

$$
\begin{aligned}
\frac{\partial C}{\partial t}= & \frac{1}{r} \frac{\partial}{\partial r}\left(r D \frac{\partial C}{\partial r}\right) \\
& \frac{\partial C}{\partial t}=D \frac{\partial^{2} C}{\partial r^{2}}+\frac{D}{r} \frac{\partial C}{\partial r}
\end{aligned}
$$

By solving the afore-mentioned equation, it is possible to obtain the amount of oxygen concentration for any section of the fuel rod, via which it would be possible to calculate the corrosion rate for Ex-reactor mode.

With regard to the diffusion equation for a fuel rod, we used Fully-Implicitly Finite Difference (finite difference) method in order to solve the afore-mentioned equation for $n+1$ time step [1].

$$
\frac{\partial C}{\partial t}=D \frac{\partial^{2} C}{\partial r^{2}}+\frac{D}{r} \frac{\partial C}{\partial r}
$$

In equations $\Delta \mathrm{t}$ and $\Delta \mathrm{r}$, the time step and node are in radial direction, and $\mathrm{i}$ represents the node number.

$$
\frac{\partial^{2} C}{\partial r^{2}}=\frac{C_{i+1}^{n+1}-2 C_{i}^{n+1}+C_{i-1}^{n+1}}{(\Delta r)^{2}}
$$

$\frac{\partial C}{\partial r}=\frac{C_{i+1}^{n+1}-C_{i-1}^{n+1}}{2 \Delta r}$

$$
\frac{\partial C}{\partial t}=\frac{C_{i}^{n+1}-C_{i}^{n}}{\Delta t}
$$

Where, $\Delta \mathrm{t}, \Delta \mathrm{r}$ and $\mathrm{i}$ refers to the time step, distance and nodes number, respectively. By substituting number into each terms of the equations, we will have:

$$
\frac{C_{i}^{n+1}-C_{i}^{n}}{\Delta t}=D \frac{C_{i+1}^{n+1}-2 C_{i}^{n+1}+C_{i-1}^{n+1}}{(\Delta r)^{2}}+\frac{D}{r} \frac{C_{i+1}^{n+1}-C_{i-1}^{n+1}}{2 \Delta r}
$$

Now, the simplification of the equation is as below:

$$
\begin{aligned}
& C_{i}^{n+1}-C_{i}^{n}=\frac{D \Delta t}{(\Delta r)^{2}}\left[C_{i+1}^{n+1}-2 C_{i}^{n+1}+C_{i-1}^{n+1}\right]+\frac{D \Delta t}{2 r \Delta r}\left[C_{i+1}^{n+1}-C_{i-1}^{n+1}\right] \\
& -C_{i-1}^{n+1}\left[\frac{D \Delta t}{(\Delta r)^{2}}-\frac{D \Delta t}{2 r \Delta r}\right]+C_{i}^{n+1}\left[1+\frac{2 D \Delta t}{(\Delta r)^{2}}\right]-C_{i+1}^{n+1}\left[\frac{D \Delta t}{(\Delta r)^{2}}+\frac{D \Delta t}{2 r \Delta r}\right]=C_{i}^{n} \\
& -R_{1} C_{i-1}^{n+1}+\left(1+2 R_{2}\right) C_{i}^{n+1}-R_{3} C_{i+1}^{n+1}=C_{i}^{n} \\
& R_{1}=\left[\frac{D \Delta t}{(\Delta r)^{2}}-\frac{D \Delta t}{2 r \Delta r}\right] \\
& R_{2}=\frac{D \Delta t}{(\Delta r)^{2}} \\
& R_{3}=\left[\frac{D \Delta t}{(\Delta r)^{2}}+\frac{D \Delta t}{2 r \Delta r}\right]
\end{aligned}
$$

The above-mentioned equation will be transformed to a matrix, as below:

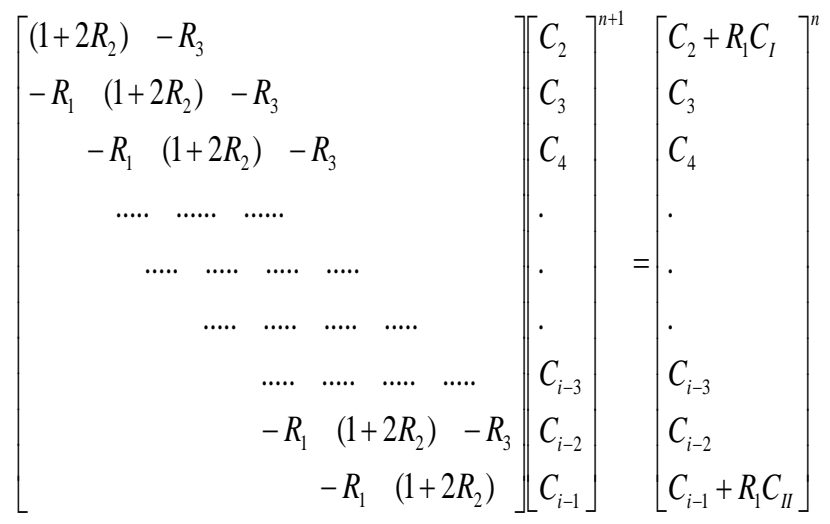

\section{BOUNDARY CONDITION}

With regard to fig. 1 and Table 1 , the boundary conditions of the problem can be extracted, then the matrix is solved [2]. 


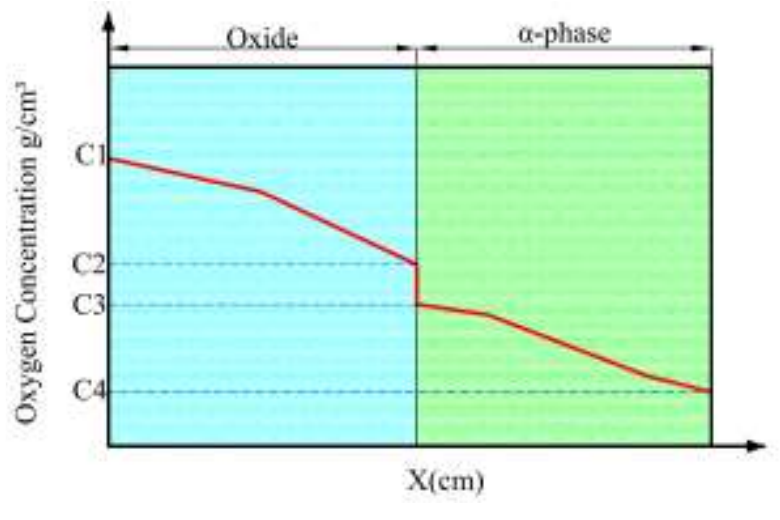

Fig. (1): Schematic of oxygen concentration in equilibrium state for $\mathrm{ZrO2}$

$\mathrm{C}_{1}$ : Oxygen concentration in equilibrium state for coolant-oxide interface

$\mathrm{C}_{2}$ : Oxygen concentration in equilibrium state for $\alpha$-Phase-oxide interface

$\mathrm{C}_{3}$ : Oxygen concentration in equilibrium state for $\alpha$-Phase.

$\mathrm{C}_{4}$ : primary Oxygen concentration in Zirconium which is equal to $9.3 \times 10^{-4} \frac{\mathrm{g}}{\mathrm{cm}^{3}}$

Table (1): Oxygen concentration in $\mathbf{g} / \mathrm{cm}^{3}$

\begin{tabular}{|c|c|c|}
\hline \multirow{2}{*}{$\begin{array}{c}\text { Concentration } \\
\text { g/cm3 }\end{array}$} & \multicolumn{2}{|c|}{ Temperature, $\mathbf{K}$} \\
\cline { 2 - 3 } & $\mathbf{2 1 7 3}$ & $\mathbf{9 7 3}$ \\
\hline $\mathrm{C}_{1}$ & 1.526 & 1.526 \\
\hline $\mathrm{C}_{2}$ & 1.3386 & 1.455 \\
\hline $\mathrm{C}_{3}$ & 0.4387 & 0.4387 \\
\hline
\end{tabular}

So, we have:

$$
\begin{aligned}
& C_{I}=1.526 \mathrm{~g} / \mathrm{cm}^{3} \\
& C_{I I}=1.5494-9.7 \times 1.0 E-5 \mathrm{~T} \mathrm{~g} / \mathrm{cm}^{3}
\end{aligned}
$$

Where, $\mathrm{T}$ denotes the temperature of external surface of the clad in Kelvin degree.

\section{MOVING BOUNDARY CONDITIONS}

With regard to the displacement of boundary layer with growth of oxide layer upon the clad of fuel rod, First Fick's Law can be rewritten as below [1]:

$$
J=\frac{d m / d t}{A}=-D \frac{d C}{d r}
$$

Where,

$\mathrm{dm}$ : the mass material diffused from $\mathrm{dr}$ in dt time (g)

A: cross-section in $\mathrm{cm}$

D: diffusion coefficient in $\mathrm{cm}^{2} / \mathrm{g}$

$\mathrm{dC}$ : concentration gradient

With regard to the afore-mentioned equation and by performing the integration from both side, we have:

$\int_{0}^{m} d m=\int_{0}^{t}-D A \frac{d C}{d r} d t$

$m=D A t \frac{d C}{d r}$

Moreover, it is possible to calculate the amount diffused oxygen mass using following equation:

$m=r A \rho \frac{n \cdot M}{M_{w}}$

Where:

r: Thickness of oxide layer $(\mathrm{cm})$

$\rho$ : Oxide density $\left(\mathrm{g} / \mathrm{cm}^{3}\right)$

$\mathrm{N}$ : atom count of oxygen

$\mathrm{M}$ : atomic mass of oxygen

$\mathrm{M}_{\mathrm{w}}$ : molar mass of oxide

$$
\text { Combining } \quad m=D A t \frac{d C}{d r} \quad \text { and }
$$

$m=r A \rho \frac{n \cdot M}{M_{w}}$ will yields following equation:

$r A \rho \frac{n \cdot M}{M_{w}}=D A t \frac{d C}{d r} \rightarrow \int_{0}^{r} A \rho \frac{n \cdot M}{M_{w}} d r=\int_{0}^{C} D A t d c \rightarrow A \rho \frac{n \cdot M}{M_{w}} \frac{r^{2}}{2}=D A t \Delta C$

$\frac{r^{2}}{2}=\frac{D A t M_{w}}{\rho n \cdot M A} \Delta C$

Following equation can be used for obtaining the thickness of oxide layer which is function of time:

$$
r=\sqrt{\frac{2 D t M_{w}}{\rho n \cdot M} \Delta C}
$$

Then, the modelling of the corrosion in Ex-reactor is done considering the oxygen diffusion coefficient, which is function of the temperature.

\section{IN-REACTOR CORROSION MODELLING}

The oxidation model for internal section of the reactor should be regarded as the developed exreactor model, which was discussed in the previous 
sections. For this purpose, a series of modifications are applied on the Ex-reactor model, including:

- Thermal flux and associated thermal gradient

- Impact of fast neutron irradiation

- Lithium concentration in primary coolant water.

\section{IMPACT OF THERMAL FLUX ON CORROSION RATE}

The power inside the reactor gets more important not only due to the thermal flux, and its impact on temperature, but also due to the formation of oxide layer and alteration of thermal conductivity coefficient of fuel clad. In what follows, the associated mathematical relations and figure are presented:

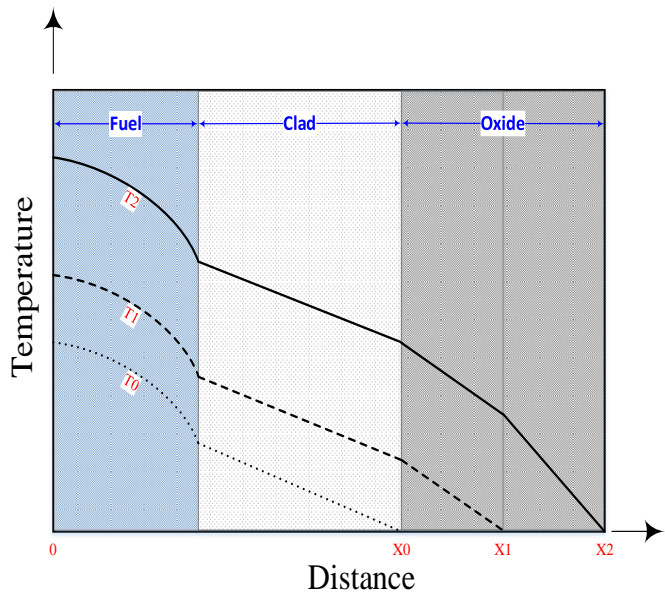

Fig. (2): Schematic of temperature profile along fuel rod in radial direction

$q_{s}=k_{c} A_{l m}^{c} \frac{\left(T_{c}-T_{i}\right)}{s}=k_{x} A_{l m}^{x} \frac{\left(T_{i}-T_{s}\right)}{x}$

$\mathrm{q}_{\mathrm{s}}$ : Heat transfer rate $(\mathrm{w})$

$$
\begin{gathered}
k_{c}: \text { Thermal conductivity } \\
\text { coefficient of fuel clad }\left(\frac{W}{m \cdot K}\right)
\end{gathered}
$$

$A_{l m}^{c}:$ Clad cross-section $\left(\mathrm{m}^{2}\right) \quad k_{x}$ :

Thermal conductivity of oxide $\left(\frac{W}{m \cdot K}\right)$

$A_{l m}^{x}$ : Oxide cross-section $\left(\mathrm{m}^{2}\right)$

$T_{s}:$ Wall

temperature $(K)$ $x$ : Thickness of oxide layer $(\mathrm{m}) \quad T_{i}$ :

Temperature of oxide-clad interface $(K$ )

$s$ : Thickness of fuel clad (m)

$T_{c}$ :

Temperature Clad-fuel interface $(K)$

Of course, the thermal conductivity coefficient of clad and oxide are function of temperature, which are presented as below $[3,4]$ : $k_{c}=7.848+2.2 \times 10^{-2} T-1.676 \times 10^{-5} T^{2}+8.712 \times 10^{-9} T^{3} \quad(W / m . K)$

$k_{x}=1.9599-2.41 \times 10^{-4} T+6.43 \times 10^{-7} T^{2}-1.94 \times 10^{-10} T^{3} \quad(\mathrm{~W} / \mathrm{m} . \mathrm{K})$

Using the afore-mentioned equations during each solving process and increase in oxide layer thickness, a new value is obtained for oxide layer:

$S^{\prime}=S-\frac{x}{P}$

Where,

$S$ : Clad thickness in time zero $x$ : Thickness of oxide layer

$s^{\prime}$ : Clad thickness in subsequent times $p$ : Pilling-Bedworth ratio $(\mathrm{P}-\mathrm{B}$ ratio)

$$
\begin{gathered}
A_{l m}^{c}=\frac{2 \pi x L}{\ln \left[\frac{R+S^{\prime}+x}{R+S^{\prime}}\right]} \\
A_{l m}^{x}=\frac{2 \pi S L}{\ln \left[\frac{R+S^{\prime}}{R}\right]}
\end{gathered}
$$

\section{IMPACT OF FAST NEUTRONS FLUX}

The irradiation of neutrons leads to increase in the corrosion rate, particularly at low temperatures, during which the corrosion rate for ex-reactor is extremely low. The fast neutrons play a key role which change the oxide structure and it radiolysis the coolant. Pyecha has developed an experimental relation for studying the impact of fast neutron which can be used in order for establishing a relation between corrosion rate within reactor and times after transition. The rate of oxidation with and without irradiation is as below [5]: 
$\frac{x^{\prime}}{x}=\frac{C_{0}+U(M \phi)^{p}}{C_{0}}$

Where,

$x^{\prime}$ :Thickness of oxide layer inside the reactor for post-transition mode

$x$ : Thickness of oxide layer corresponding to reactor outside

$\phi$ : Fast neutrons flux $\left(\frac{n}{\mathrm{~cm}^{2} \cdot \mathrm{sec}}\right)$

$C_{0}=8.04 \times 10^{7}(\mu m / d)$

$$
U=2.59 \times 10^{8}(\mu \mathrm{m} / \mathrm{d})
$$

$$
\begin{gathered}
M=7.46 \times 10^{-15} \quad \mathrm{~cm}^{2} \cdot \mathrm{sec} / \mathrm{n} \\
P=0.24
\end{gathered}
$$

Substituting numerical values into the afore-mentioned initial equation will yield:

$$
\frac{x^{\prime}}{x}=\frac{8.04 \times 10^{7}+2.59 \times 10^{8}\left[7.46 \times 10^{-15} \phi\right]^{0.24}}{8.04 \times 10^{7}}
$$

The afore-mentioned value is known as the increase coefficient which is resulted due to the presence of fast neutrons in corrosion rate.

$\frac{x^{\prime}}{x}=1+3.2214\left[7.46 \times 10^{-15} \phi\right]^{0.24}$

\section{CHEMICAL IMPACT OF REACTOR WATER}

A slight variation in chemical properties of the coolant water generates Lithium hydroxide and other chemical substances which can lead to alterations in oxidation kinetic. For example, Lithium hydroxide is used for preserving the primary water system in alkaline conditions in order to regulate corrosion productions amount of insoluble for coolant. This action leads to mitigation in the amount of radioactive metals dissolved in the coolant, as well as reduction in resistance to Zircaloy corrosion, due to the presence of Lithium hydroxide [6].

$K_{r}^{0}=B C_{a v}^{0}$

$K_{r}^{0}$ : Kinetic rate constant for pure zirconium oxide

B: constant value
$C_{a v}^{0}$ : Equilibrium concentration fills the anion vacancy, due to the absence of corrosion productions ion (av stands for anion vacancy).

In what follows, a relation for corrosion kinetic ratio regarding the presence and absence of Lithium is presented:

$\frac{K_{r}}{K^{0}}=1+\frac{3\left[\mathrm{Li}^{+}\right]_{\mathrm{ZrO}_{2}}}{2 C_{a v}^{0}}$

Where,

$K_{r}$ : Kinetic rate in the presence of $\mathrm{Li}^{+}$in oxide

$\left[\mathrm{Li}^{+}\right]_{\mathrm{Zro}_{2}}$ : Lithium concentration in Zirconium oxide

$C_{a v}^{0}$ : Equilibrium concentration fills the anion vacancy (almost equal to $2 \times 10^{21}$ in volume unit $\left(\mathrm{cm}^{3}\right)$ Zirconium oxide)

$\left[\mathrm{Li}^{+}\right]_{\mathrm{ZrO}_{2}}=\mathrm{D}\left[\mathrm{Li}^{+}\right]_{\mathrm{H}_{2} \mathrm{O}}$

In the afore-mention equation, $\mathrm{D}$ refers to the diffusion coefficient which is a constant value and it is averagely equal to 5. By assuming $1 \mathrm{ppm}\left[\mathrm{Li}^{+}\right]_{\mathrm{ZrO} 2}=5 \times 10^{17}\left(\mathrm{atomsLi} / \mathrm{cm}^{3}\right) \mathrm{ZrO}_{2}$, then:

$\left[\mathrm{Li}^{+}\right]_{\mathrm{ZrO}_{2}}=5 \times 10^{17} \mathrm{D}\left[\mathrm{Li}^{+}\right]_{\mathrm{H}_{2} \mathrm{o}}$

$\left[\mathrm{Li}^{+}\right]_{\mathrm{Zro}_{2}}: \mathrm{Li}^{+}$Lithium concentration in (atoms $\left./ \mathrm{cm}^{3}\right) \mathrm{ZrO}_{2}$ oxide

$\left[\mathrm{Li}^{+}\right]_{\mathrm{H}_{2} \mathrm{O}}: \mathrm{Li}^{+}$Lithium concentration in ppm water

With regard to the afore-mentioned relations, a simple relation related to the role of Lithium concentration in zirconium corrosion can be obtained:

$$
\begin{aligned}
& \frac{K^{\prime}}{K_{r}^{0}}=1+\frac{3 \times 5 \times 10^{17} \times 5\left[\mathrm{Li}^{+}\right]_{\mathrm{H}_{2} \mathrm{O}}}{2 \times 2 \times 10^{21}} \\
& \frac{K_{r}}{K_{r}^{0}}=1+1.875 \times 10^{-3}\left[\mathrm{Li}^{+}\right]_{\mathrm{H}_{2} \mathrm{O}}
\end{aligned}
$$

In the afore-mentioned relation, Lithium 
concentration in the water is ppm, for expressing the concentration in $($ moles/liter $)$, the above relation should be re-written as below:

$$
\frac{K_{r}}{K_{r}^{0}}=1+13.125\left[\mathrm{Li}^{+}\right]_{H_{2} \mathrm{o}}
$$

\section{Methods}

Fig. 3 depicts the flowchart of computation program. The structure of the flowchart is in such a way that, in the first phase it is necessary to calculate the fluid equations, which is followed by fuel equations and gap heat transfer coefficient, corrosion, etc., then the corrosion modelling for Ex-reactor is accomplished. Finally, the corrosion rate for clad of fuel rod of Bushehr Reactor was calculated considering the factors resulting from effects inside the reactor (i.e. the results import section or solving the Thermohydraulic part of the problem) [9].

\section{RESULTS}

In this section, the calculations associated with the oxide layer in Ex-Reactor are accomplished using data of VVER-1000 Reactor [7, 9]. Since the flux of the fast neutrons and $\mathrm{LiOH}$ concentration, as well as the thermal flux and clad temperature should be specified for calculating the oxide layer in Ex-Reactor, so it is essential to adopt a conservative approach, in such a way that the temperature and maximum flux should be taken into account for performing the calculations.

Regarding the data obtained from first cycle of the BNPP Reactor and using the maximum value of the thermal flux in the hottest channel of the reactor core, the variation in the linear thermal flux during the first cycle are depicted by fig. 4 .

The value of the maximum external temperature of the fuel clad and the maximum surface thermal flux during the first cycle of
VVER-1000 Reactor are presented in the Table 2.

Table 2: Value of the maximum external temperature of the fuel clad and the maximum surface thermal

\begin{tabular}{|r|rr|}
\hline $\begin{array}{r}\text { Maximum outside } \\
\text { temperature of fuel } \\
\text { clad }(\mathrm{K})\end{array}$ & $\begin{array}{r}\text { Maximum } \\
\text { surface } \\
\text { thermal flux }\end{array}$ \\
\hline$T_{C O_{\max }}=627.2(\mathrm{~K})$ & $q_{\max }^{\prime \prime}=62.3\left(\frac{\mathrm{W}}{\mathrm{cm}^{2}}\right)$ \\
\hline
\end{tabular}

Moreover, the flux of fast neutrons and $\mathrm{LiOH}$ concentration are equal to $2 \times$ $10^{12}\left(\frac{\#}{\mathrm{~cm}^{2} \cdot \mathrm{sec}}\right) \quad$ and $10^{-03}\left(\frac{\text { mole }}{\text { litre }}\right)$, respectively. The duration of radiation was assumed to be equal to first cycle of VVER1000 Bushehr Reactor or 290 days [8].

The calculations are done based on the afore-mentioned relations. Fig. 6 shows the changes to oxygen concentration in the fuel clad (Zicaloy-4) upon certain time steps.

The increase trend in the oxide layer thickness for the Ex-reactor regardless of the Inreactor conditions, like thermal flux, etc. is illustrated by Figure 5 .

As it was mentioned, inside the reactor there are important factors which contribute to the growth trend of the oxide layer and corrosion rate. These factors are as follows:

- Thermal flux and the associated thermal gradient

- Significant impact of neutron radiation

- Lithium concentration in the primary coolant water

In what follows, each factor role and contribution are depicted by the curves. 


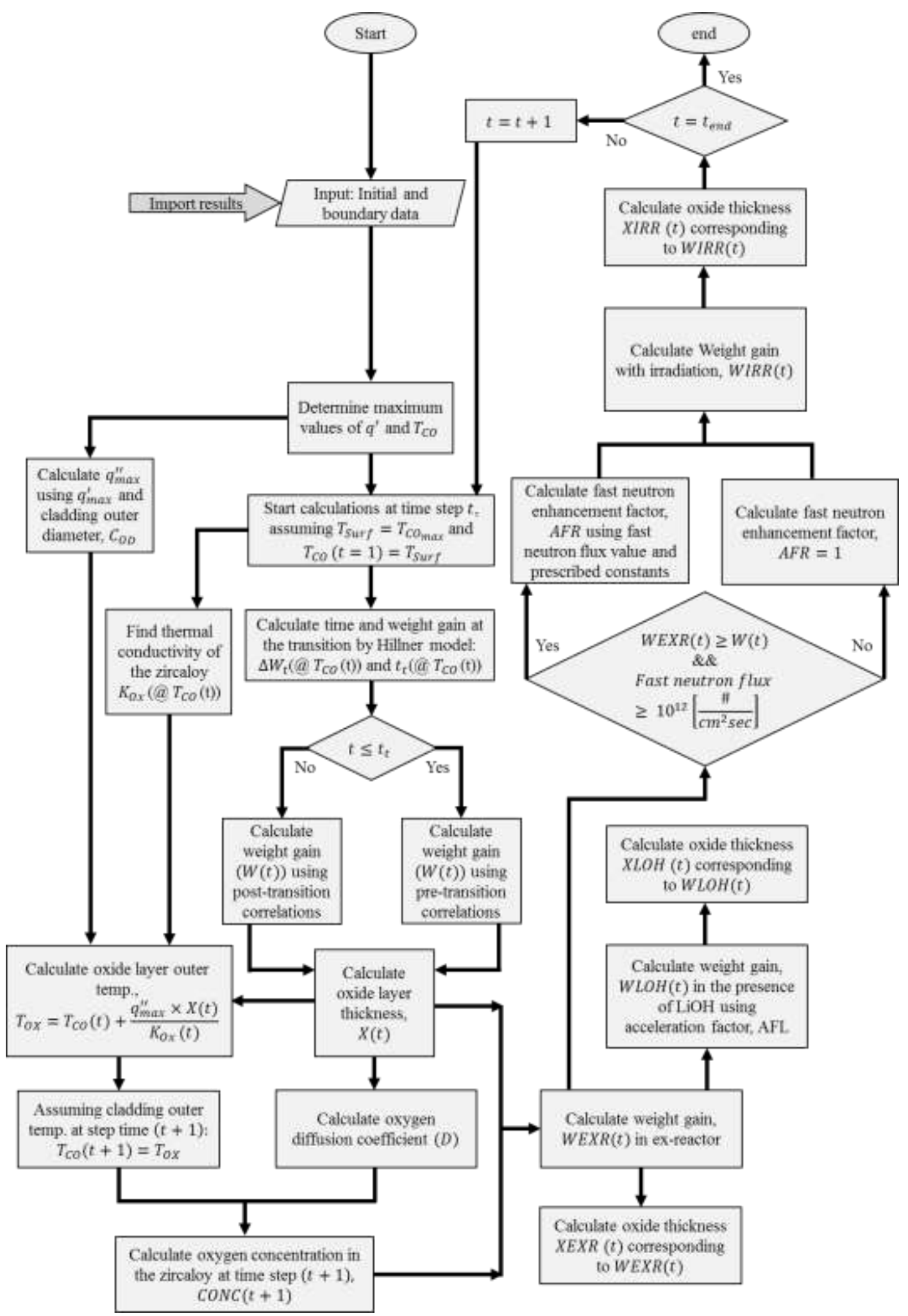

(c)

Fig. (3): Flowchart for computation of corrosion rate associated with Ex-reactor 


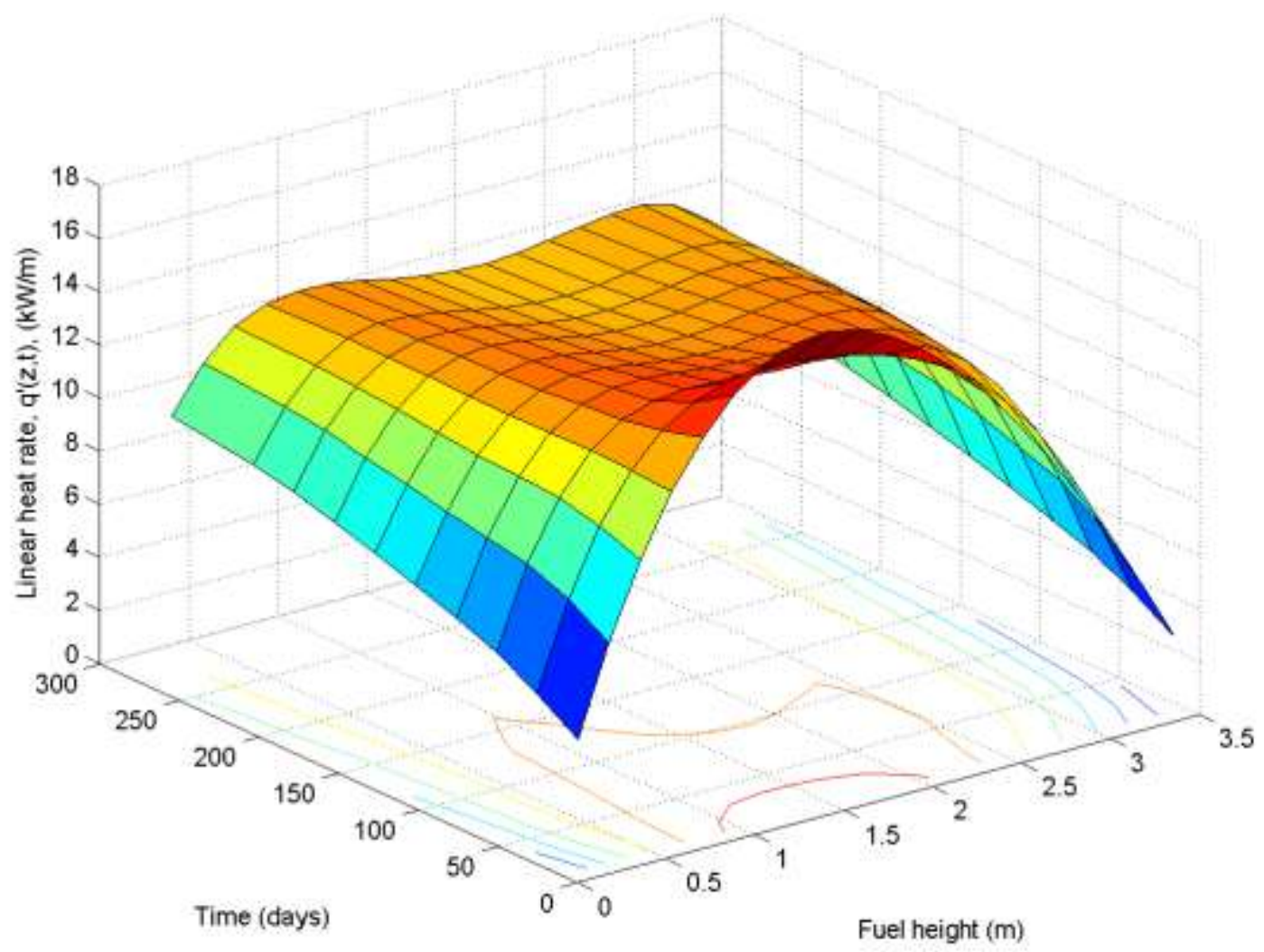

Fig. (4): Variation in linear thermal flux along the hottest channel during the first cycle of VVER-1000 Bushehr Reactor

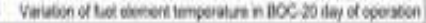

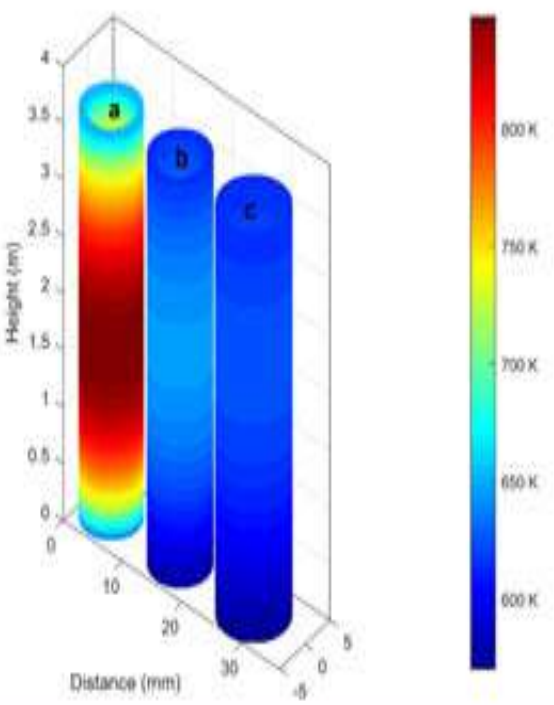

Fig. (5): Temperature changes in the outer surface of the fuel (a) The inner surface of the clad (b) and the outer surface of the clad (c) in line with the height of the hot channel in the first cycle of Bushehr reactor in 5 time steps

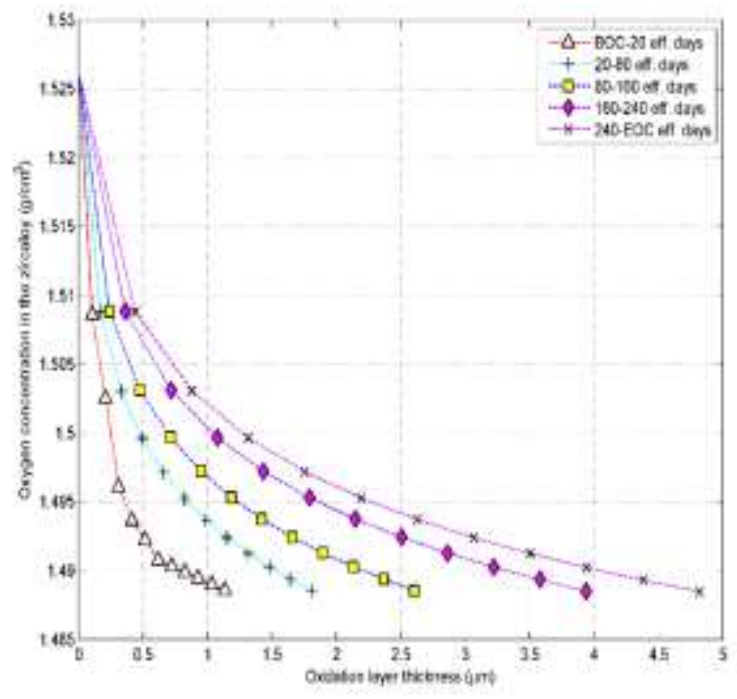

Fig. (6): Variation in oxygen concentration of fuel clad within the oxide layer of the first cycle of VVER-1000 Bushehr Reactor 


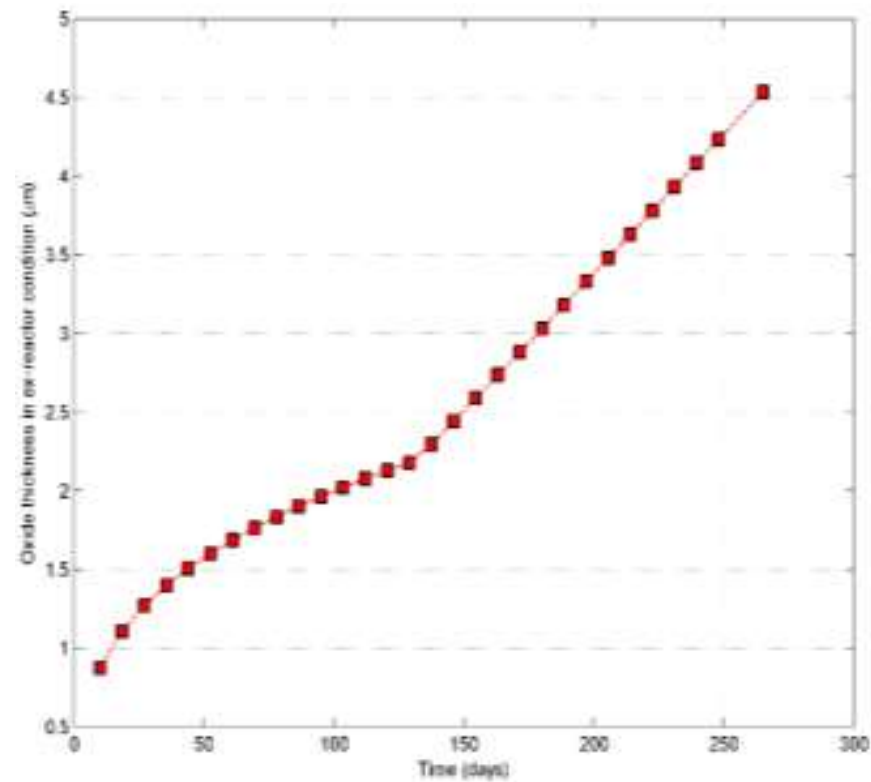

Fig. (7): Increase trend of oxide layer thickness over the fuel clad in Ex-reactor conditions within single cycle of VVER-1000 Bushehr Reactor

Figure 7 presents the comparison made between the increase trend of oxide layer computed for Ex-reactor condition and condition with presence of Hydroxide Lithium ( $\mathrm{LiOH})$.

Based on this figure, it is obvious that Lithium hydroxide makes ineffective contribution to the increase of oxide layer thickness.

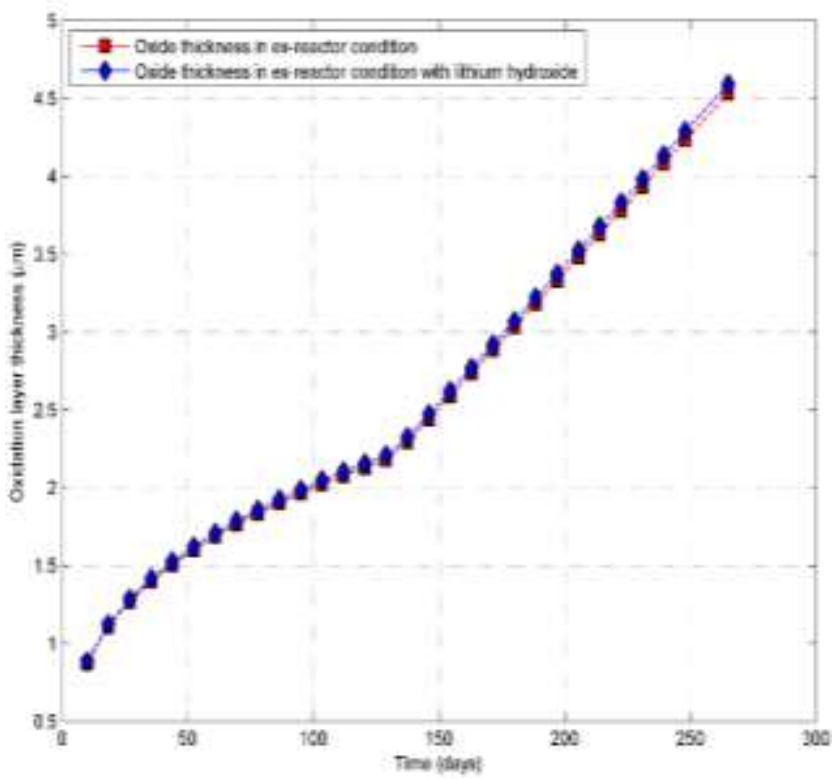

Fig. (8): Comparison between the increase trend of oxide layer over the fuel clad for Ex-reactor condition and condition with Lithium hydroxide ( $\mathrm{LiOH})$ within single cycle duration of BNPP
Figure 8 presents the amount of oxide layer thickness under condition with various concentrations of lithium hydroxide.

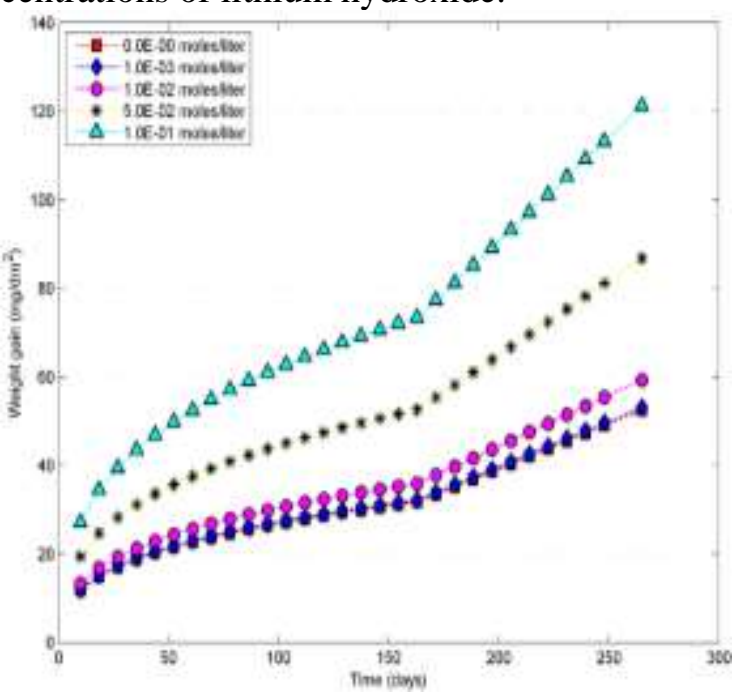

Fig. (9): Comparison between the increase trend in oxide layer thickness upon fuel clad for Ex-reactor conditions and condition with presence of various concentrations of lithium hydroxide ( $\mathrm{LiOH}$ ) within single cycle time period of VVER-1000 Bushehr Reactor

Figure 9 presents the comparison made between the increase trend of oxide layer thickness for Ex-reactor conditions with/without thermal flux and radiation condition.

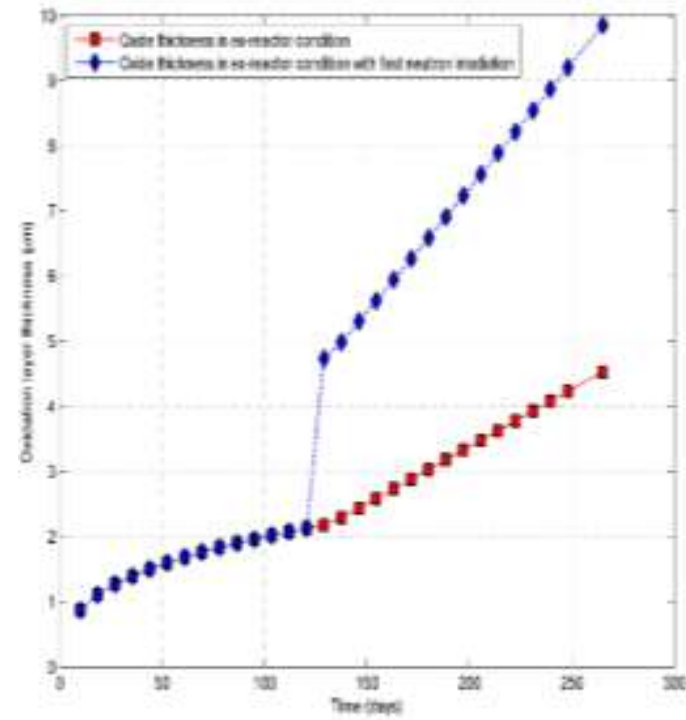

Fig. (10): Comparison between increase trend of oxide layer thickness upon fuel clad for Ex-reactor with/without fast neutron flux within single cycle time of VVER-1000 Bushehr Reactor 
Figure 9 and 10 show the amount of oxide layer for various conditions of fast neutron flux and different thermal degrees, respectively.

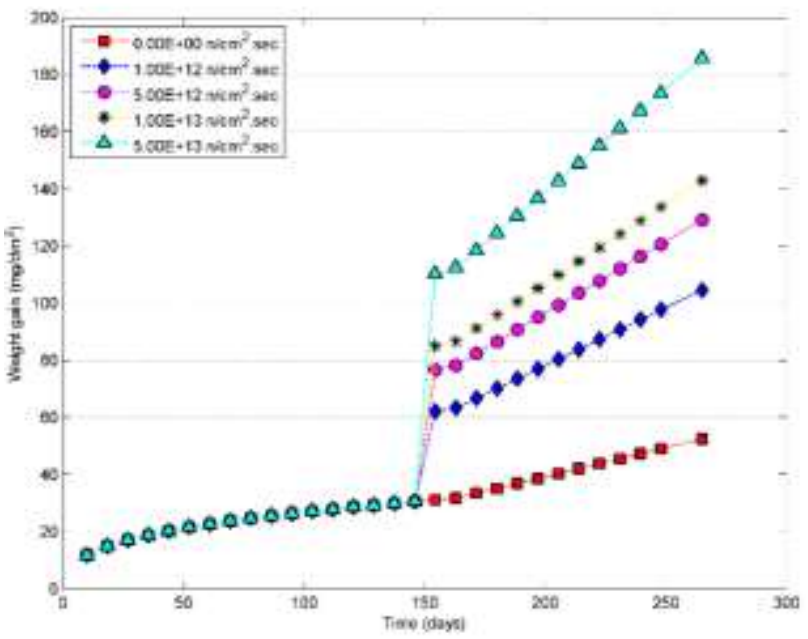

Fig. (11): Comparison between increase trend of oxide layer thickness upon fuel clad for Ex-reactor condition and various fluxes of fast neurons within single cycle of VVER-1000 Bushehr Reactor

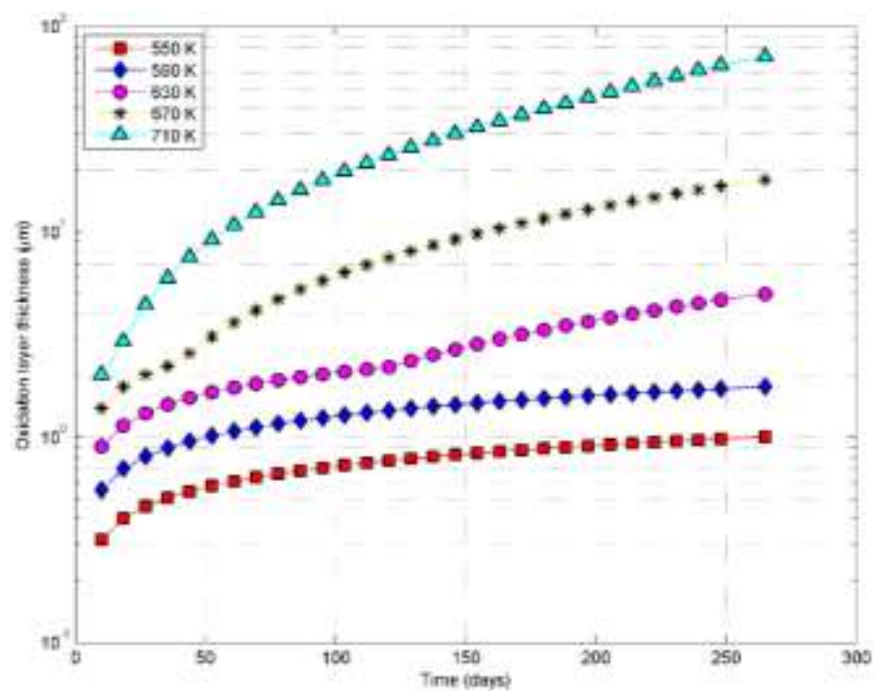

Fig. (12): Comparison between the increase trend of oxide layer thickness upon the fuel clad under various thermal conditions within single cycle of VVER-1000 Bushehr Reactor

With regard to the amount of oxide layer and the contribution of the effective factors presented in Figure 11, it is obvious that the fast neutrons make a significant contribution to the growth trend of the oxide layer thickness.

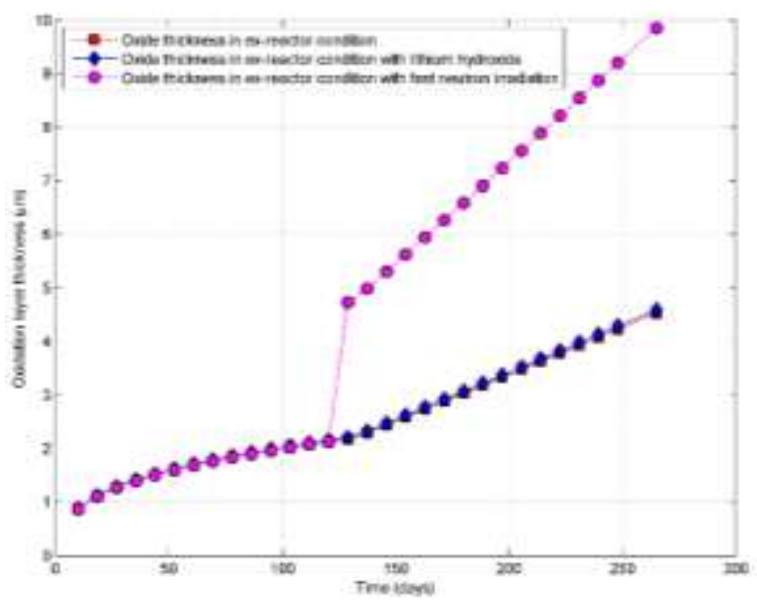

Fig. (13): Comparison between increase trend of oxide layer thickness upon fuel clad for various conditions and effect of each contribution within single cycle of VVER1000 Bushehr Reactor

\section{Conclusions}

As the oxidation rate of the fuel clad is an important factor in fuel designation, so its calculation for Ex-reactor and In-reactor conditions is of high importance. The accomplished calculations can be utilized in designing the fuel clad under various conditions in which the reactor is located, which will provide the ground for screening the effect and contribution of each Inreactor factor, including radiation and chemical effects of reactor water on the corrosion rate of the fuel clad.

\section{Authors' contributions}

The manuscript was written by L. Ramezani, and scientific supervision was done by M. Mansouri and M. Rahgoshay

\section{References}

1. Crank, J. (1979) The Mathematics of Diffusion, Oxford University Press, Oxford.

Zumpicchiat, G., Pascal, S., Tupin, M. and Berdin-Méric, C. (2015)

2. Finite element modelling of the oxidation kinetics of Zircaloy-4 with a controlled metaloxide interface and the influence of growth stress, Corros. Sci, 100, 209-221.

3. Wagner, C. and Schottky, W. (1930) Theory of controlled mixed phases, Zeitschrift für Physikalische Chemie, 11, (2/3), 163-210. 
4. Ursu, I. (1985) Physics and Technology of Nuclear Materials, Pergamon, New York, NY.

5. Pyecha, T. D., et al. (1985), Light Water Reactor Performance, US Department of Energy Report, DOE/NE/34130-

1.

Hillner, E. and Chirigos, J.N. (1962) The Effect of Lithium Hydroxide and Related Solutions on the Corrosion Rate of Zircaloy in $680^{\circ} \mathrm{F}$ Water, Bettis Atomic Laboratory Report, Westinghouse Electric Corporation, WAPD-TM-03.

6. Final Safety Analysis Report (FSAR). (2003) Chapter 4, Revision 0, Moscow.

7. Water Chemistry of the Primary System, 49. BU.1 0.0.OO. FSAR.RDR001

Ramezani, L., Mansouri, M. and Rahgoshay, M. (2018) Modeling the water side corrosion and hydrogen pickup of the vver1000 fuel clad, Nucl. Technol. Radiat. Nucl, 33 (4), 334-340. 